\title{
Structural Engineering by way of BIM
}

\author{
Wiesław Baran ${ }^{1}$, and Bartosz Żymańczyk ${ }^{2 *}$ \\ ${ }^{1}$ Opole University of Technology, Faculty of Civil Engineering and Architecture, Katowicka 48, \\ 45-061 Opole, Poland \\ ${ }^{2}$ Adamietz Sp. Z o.o., General Contractor, Braci Prankel 1, 47-100 Strzelce Opolskie, Poland
}

\begin{abstract}
BIM idea is increasing the productivity of work. Multidimensional solutions implemented in BIM systems not only allow many structural calculations, but also access the better scheduling, cost estimating, visualizations. In some cases both software and hardware can be a bottleneck. To create an interaction between BIM philosophy and practice of the structural design the experimental research has tested eight structural systems of the high-rise building by way of Building Information Modelling. Multiple variants of the two main bracing system types: (i) a spatial truss and (ii) a spatial shell bracing system. In every model there was checked influence of slab model: with slabs meeting the conditions of a rigid plate (flexible diaphragm slab) and with slabs with no additional stiffening (shell slab). The ULS and SLS requirements were analysed for elements and superstructure. In addition, selected issues concerning scheduling of works (4D BIM) and cost estimating (5D BIM) were discussed with the extensive 3D model developed in line with the BIM standards. Rapid prototyping has enabled to realize the behaviour of structural systems. The outputs of this study are presented in the paper.
\end{abstract}

\section{Introduction}

Civil engineers worldwide constantly look for solutions increasing their productivity of work, in design offices or construction sites. The ex-potential increase in the IT area, including growth of PC computing power contributes to dissemination of computer-aided methods in civil engineering. With regard to the need for industry support integration, but also need of data exchange between business partners involved in the investment project, at the end of the 1990s firms responsible for CAD systems accelerated the development of Product Data Management (PDM) systems. The systems are a product central database. The computeraided design technologies in Civil Engineering began their evolutionary process into Building Information Model/Modelling/Management (BIM) system. It is anticipated that the phenomenon will significantly impact on job of any entity associated with civil engineering [1]. BIM procedure is a combination of stages of the design process, investment project and facility lifecycle. Model that complies with BIM philosophy stands for modern approach to designers joint work by integrating intelligent objects into one file. The objects may contain all information pertaining to components concerned and its functions, understanding

\footnotetext{
*Corresponding author: bartosz.zymanczyk@adamietz.pl
} 
allegiance to the model and correlation with another objects in a multidimensional form, eg. geometric dimension.

$\mathrm{BIM}$ is a multidimensional work environment with large amounts of controlled data processed real-time in object lifecycle. The idea of collaboration has its origins in prestigious design offices from years ago, when building process participants exchanged data while being in the same room. Nowadays, civil engineers and structural engineers may take advantage of BIM virtues in many ways. Solutions and elements implemented to the BIM model successively are visible to all file-accessed users by linking information technology solutions (eg. cloud storage) delivering absolutely current model version real-time [2]. From the perspective of Structural Engineer the quality of his work on venture is growing. BIM philosophy influences on conceptual design works, structural analysis and delivery of detailed technical documentation (eg. drawings). It eliminates design faults, drafting errors and system collisions, reducing workload and its price in design process, all leading to increase of productivity. Solutions implemented in BIM systems access the better scheduling (4D BIM) and cost estimating (5D BIM), which ultimately affect competitiveness of design offices. BIM models provide many IT solutions allowing for integration of sustainability analysis such as daylight analysis, water harvesting, and thermal assessment.

One aspect of the work with BIM model is visualization of a building as 3D rendering. The latest software allows model design and virtual walkthrough in virtual reality (VR). For the first time this technology was used in 1968 by I. Sutherland allowing him virtual walkthrough in a wireframe room [3]. Simulation as regards virtual presentation of an object, eg. Building in scale model with all the details (BIM Level of Detail 350-500) may potentially help structural engineer in structure bearing elements design, identifying flaws or selecting better solutions unleashing creativity [4].

The paper, by example of high-rise steel structure building design, will discuss the state of progress and knowledge on building information modelling and its influence on civil engineering. The review will examine the potential benefits of productivity, management, consistency of information, analyses and simulations, visualization to present the impact will be felt by BIM in the civil engineering.

Eight structural systems were designed with orthogonal size $25.0 \times 25.0 \mathrm{~m}$ and height of $192.0 \mathrm{~m}$ using BIM philosophy. There was used BIM-based file synchronization software. There were presented virtues coming from the collaboration in the BIM environment by way of design, structural analysis and change of structural bearing elements, concluding their impact.

\section{Description of numerical analysis}

\subsection{Finite elements model}

Steel structure of projected high-rise building was inscribed into a square massing form with its size of $25.0 \times 25.0 \mathrm{~m}$ at the side and $192.0 \mathrm{~m}$ of height. Numerical models contain bar elements (columns and beams) and shell elements (3, 4 - nodal) for curtain walls and slabs with meshing element size of $0.5 \mathrm{~m}$. The fixed joints of columns and reinforced concrete foundation boxes were posited.

There 2 types of bracing systems were posited: a spatial truss bracing system $(\mathrm{R})$ and a spatial shell bracing system (P) 

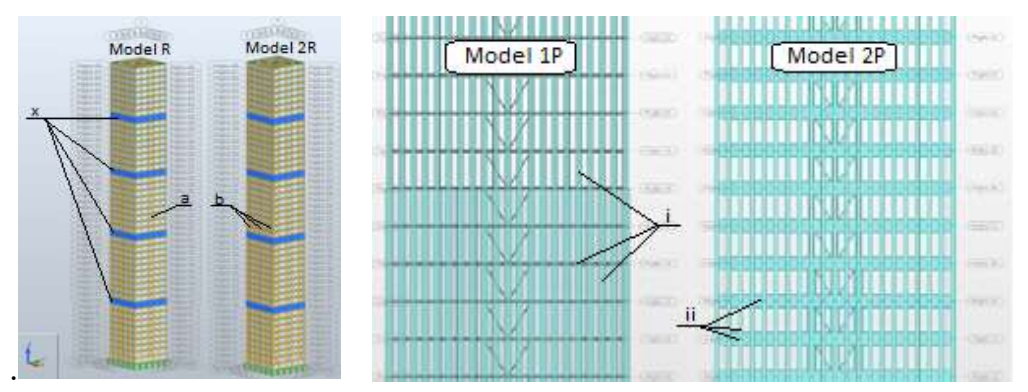

Fig.1. Calculation models a) structural frames with K-truss stiffening as single trail (type 1R) and triple trail (type $2 \mathrm{R}$ ); b) structural shell bracing system in two variants of the coating design: (type $1 \mathrm{P}$ and type $2 \mathrm{P}$ ) - description in the text.

A spatial truss bracing system (R). Main structural role are steel frames carrying vertical and horizontal loads with different truss bracing systems. Trusses stiffening longitudinal and lateral frames were designed uniformly due to a square plan cross-section of the high-rise building. K-truss stiffening was assumed in orthogonal directions: " $a$ " - in one of five (type $1 R$ ) or " $b$ " - in three of five (type 2R) frame naves. Additional, there were assumed peripheral truss-bracings (" $x$ " in the Fig. 1) with horizontal grid structures at 4 levels of total height. That reduced the strain of columns sharply increased the global stiffness of a structure. Because of the potential for attending slabs in loads redistribution there were designed calculation models with slabs meeting the conditions of a rigid plate (flexible diaphragm slab) and with slabs with no additional stiffening (shell slab) - 4 models in total.

A spatial shell bracing system (P). Spatial stiffness of the structure is ensured by high density of columns (spacing $1.25 \mathrm{~m}$ ) rigidly connected to beams in the outline of a building - structural shell. Two types of shell-coating structure were modelled: (i) columns with a cross-section rising and steel grade changing above the height constantly and with low profiled beams (Fig. 1) - type 1P; (ii) columns with a constant cross-section and steel grade changing above the height constantly and with high profiled beams (Fig. 1) - type 2P. Additionally, in the center of a building cross-section there was placed a K-truss stiffened core. A superstructure was made of internal frames with main columns rigidly connected to binders stiffened with longitudinal and lateral bolts (hinge joints). Bolts created a grid structure for concrete slabs and distributed internal loads between shell structure and core. As before, 4 calculation models were designed in total, with slabs meeting the conditions of a rigid plate (flexible diaphragm slab) and with slabs with no additional stiffening (shell slab). Constant parameters in calculation models:

- Axial dimensions: 25.0 x 25.0 x $192.0 \mathrm{~m}$,

- $\quad$ 48-storey office building, level one with $8.0 \mathrm{~m}$ of height,

- Rigid joints between columns and foundation boxes,

- Hinge joints between vertical bracings and columns,

- Hinge joints between horizontal bracings with beams,

- The two-way supported reinforced lightweight concrete slab floors (LC25/28),

- Box section columns and beams (no lateral - torsional buckling),

- Steel skeleton of a building (Steel S275, S355, S460),

- Elevations in Autodesk Robot system made of "Claddings". 


\subsection{Applied loads}

Decisive influence on high-rise building structure have vertical and horizontal wind loads and foundation conditions. Structural system should be lightweight, however lowering the weight influences on dynamic, acoustic aspects and fire protection requirements. In analysed models the loads were adopted according to Eurocode [13, 14, 15].

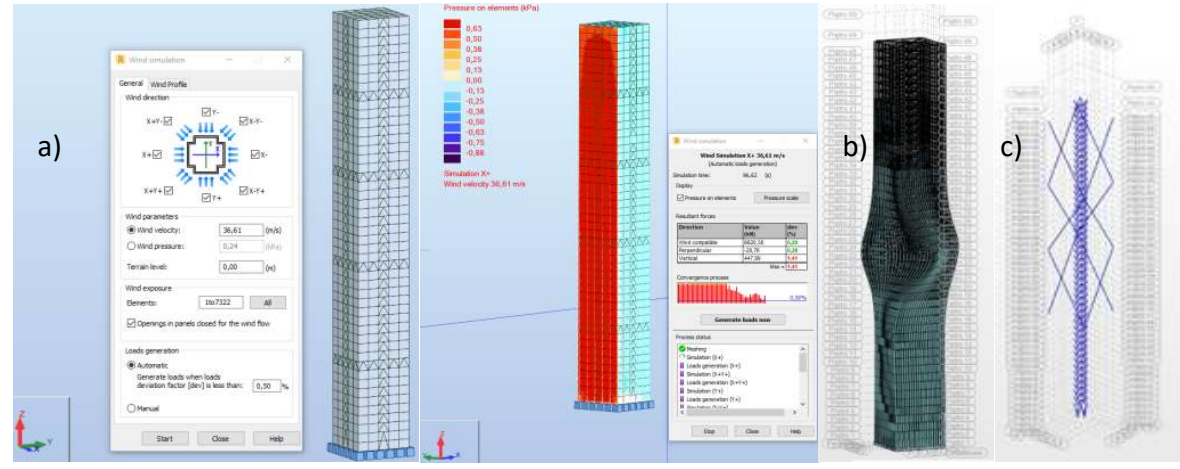

Fig.2 Wind loads: a) Autodesk Robot wind simulation; b) torsional deformation; c) structural core with new coating bracing system.

To object located in Opole, snow load equals $0.72 \mathrm{kN} / \mathrm{m}^{2}$. Service loads equal to 3.0 $\mathrm{kN} / \mathrm{m}^{2}$ were designed as planar loads applied to slab surfaces with the selected adverse way. To pre-set peak value of wind speed $\left(\mathrm{v}_{\mathrm{m}}=36.61 \mathrm{~m} / \mathrm{s}\right)$ loads were generated in Robot system with its "wind simulation" module. Only claddings and panels were under load, with simulation set in 8 directions. With an advanced wind simulation (Fig. 2a) there was identified vulnerability to torsion of shell model with "flexible diaphragm" slabs. Revision of the model and blocking the rotation of the element nodes, and therefore the lack of torsion effects redistribution from columns to reinforced concrete slabs have caused significant effort of all columns, binders and bracings within structure's center of gravity. Quarter wind was the cause of the torsion effects, computational analysis shown. A wind pressure from one of the intercardinal points. To counteract torsion effects there were applied additional structural shell columns' bracings (Fig. 2c).

\subsection{Functional requirements}

Eurocode limit state design requires some criteria to structural elements in terms of Serviceability Limit State (SLS) on the basis of vertical displacements or vibrations. Deflection of the structure is an important limit for high-rise building, which also depends on the bracing system. Referring to US codes (ASCE/SEI 7) [18], deflection have an effect: on load-bearing capacity as a result of the dynamic effects; on curtain walls and installation systems work; on well-being of people inside the building. The codes (ASCE 7) assume as acceptable deflection of a high-rise building node: $\mathrm{f}=\mathrm{H} / 500 ; \mathrm{f}[\mathrm{m}]$ is node deflection, $\mathrm{H}[\mathrm{m}]$ is building height.

For designed building structure condition is presented as: $\mathrm{f}<0.384 \mathrm{~m}$. Structure stiffness decides of deflection effects, and I can be limited globally with choose the appropriate bracing system. The values of nodal global deflection of the eight analysed calculation models are fiven in Table 1. Using flexible diaphragm slab reinforces structure increases its stiffness and reduces global deflection additionally. The largest deflection was obtained by model type 1R (shell slab), the slightest by model type 2P (flexible diaphragm slab). Despite 
meeting the conditions for the ultimate limit state (ULS) and the serviceability limit state (SLS) three models did not meet the required value of deflection.

Table 1. Global deflections of analysed models.

\begin{tabular}{|c|c|c|c|}
\hline \multirow{2}{*}{ Model type } & \multicolumn{2}{|c|}{ Global deflection } & \multirow{2}{*}{ In relation to 1R (Shell) model } \\
\cline { 2 - 3 } & $\mathrm{X}[\mathrm{mm}]$ & $\mathrm{Y}[\mathrm{mm}]$ & \\
\hline 1R / Shell & -447 & 449 & $\mathbf{1 0 0 \%}$ \\
\hline 1R / Diaphragm & -431 & 432 & $-4 \%$ \\
\hline 2R / Shell & 246 & 246 & $-45 \%$ \\
\hline 2R / Diaphragm & 234 & 234 & $-48 \%$ \\
\hline 1P / Shell & -421 & 425 & $-6 \%$ \\
\hline 1P / Diaphragm & -319 & 320 & $-29 \%$ \\
\hline 2P / Shell & 289 & 292 & $-35 \%$ \\
\hline 2P / Diaphragm & 161 & 162 & $-64 \%$ \\
\hline
\end{tabular}

\section{Types of computational analysis}

The definition of the construction system of the high building is dependent on how the usable surface is formed, and above all, the number of tiers above ground. Slabs carry permanent and variable loads on beams, pillars and walls. Slabs are required to be made in large span and low section heights, they must also meet the requirements of fire resistance and allow installations. The slab, as a horizontal shield, allows for a transmission of horizontal forces onto other structural elements (pillars, concentration systems).

Table 2. Shell slab model $-47^{\text {th }}$ floor.

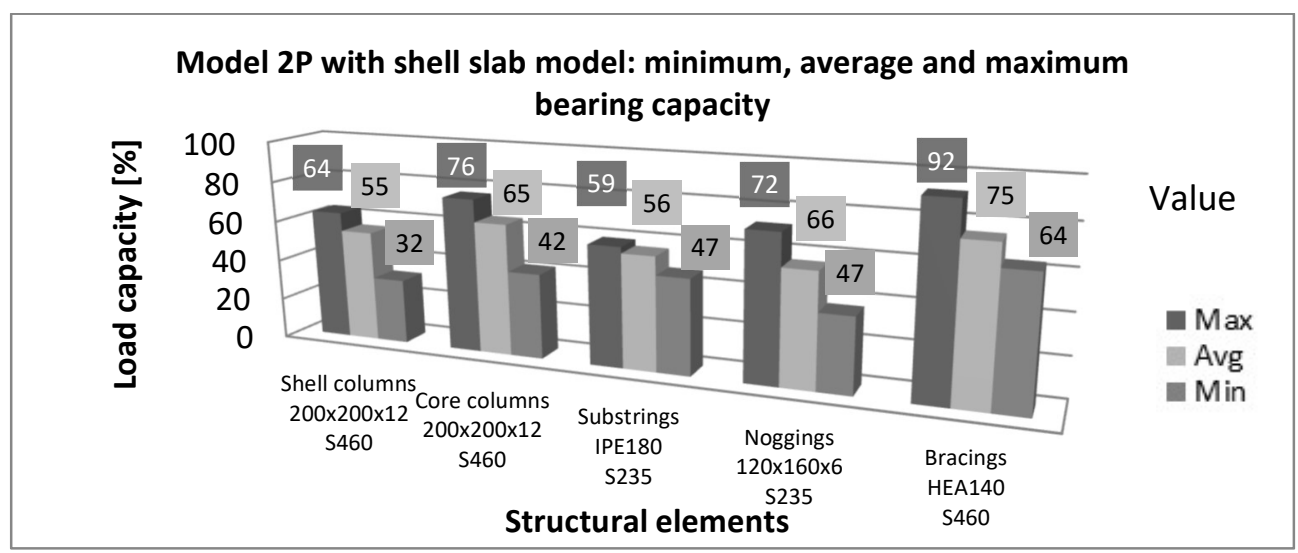

Building various models of high buildings, you need to be aware of the nature of the work and functions of slabs. In the models of skyscraper, the "shell" type slab assumes that horizontal loads are transferred to vertical bracing systems only by flat lattice bracing systems. The "diaphragm" type slab assumes that the slabs meet the condition of the rigid plate and they carry horizontal loads on the bracing systems. Stiffening diaphragm gives rigid connections to all nodes in the same plane and slab contour, blocking the degrees of freedom in the horizontal plane in both directions. Effects of interactions analysis showed, that the use of stiffening the construction with the diaphragm's type slabs affects the growth of 'effort of structural components like pillars and beams (compare Tables 2-3), simultaneously leading to drop in global node displacements. However, effort of bracing falls, and stresses from 
these elements are partially taken by slabs with the properties of the rigid discs. In the modeled structure, the inclination of stem decreased after application of the diaphragm slab type model even by $64 \%$ for $2 \mathrm{P} / \mathrm{Diaphragm}$, with relation to the output model $1 \mathrm{R} / \mathrm{Shell}$.

Table 3. Flexible diaphragm slab model $-47^{\text {th }}$ floor.

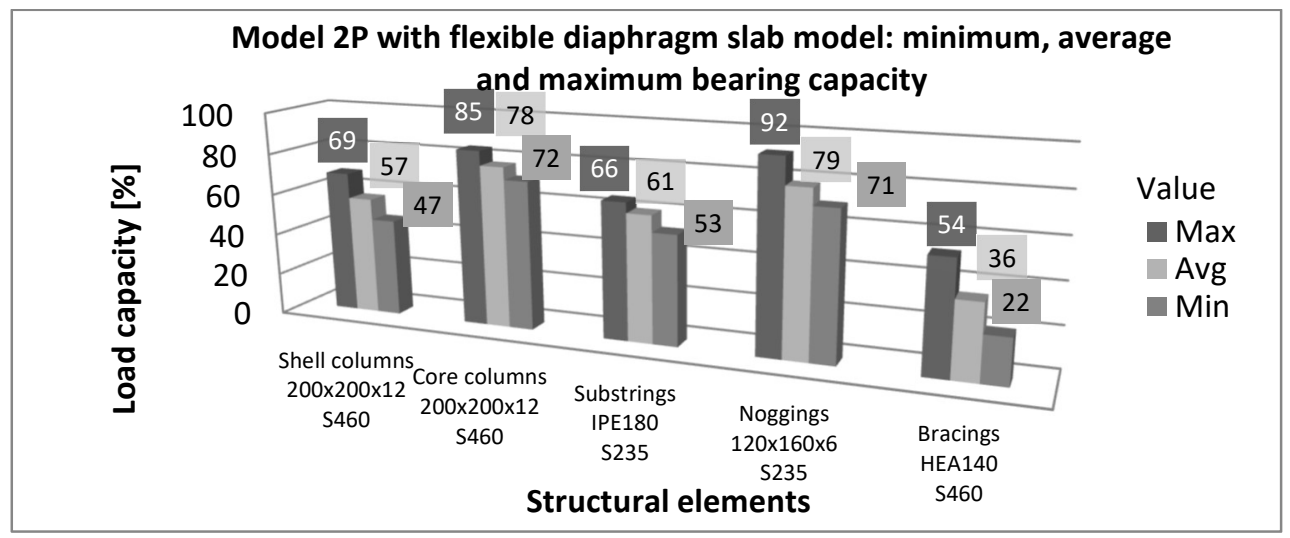

High rise building design necessitates advanced calculations and places high expectations to experienced structural engineers. Many elements negligible in low buildings must be considered in calculations. These include impact assessment of deflection on quantities of internal forces and bending moments, torsion stiffness, dynamic response and its influence on gusts of wind parameter or reduction of global stiffness from scratch on reinforced concrete elements. Also nonlinear analysis influence shall be assessed. Robot system inspected the models for influence of nonlinear analysis in terms of: geometry and physics using the Newton-Raphson iterative process updating the stiffness matrix after each iteration. Linkage between ULS and nonlinear analysis in calculation models resulted in increase of bearing capacity up to $10 \%$ (columns).

Table 4. Calculation models summary [9].

\begin{tabular}{|c|c|c|c|c|c|}
\hline No. & $\begin{array}{c}\text { Model } \\
\text { type }\end{array}$ & Analysis type & $\begin{array}{c}\text { Number Of Elements, Finite } \\
\text { Elements Analysis }\end{array}$ & Nodes & Equations \\
\hline 1. & $2 \mathrm{R}$ & Linear analysis & 149032 & 123 & 740286 \\
\hline 2. & $2 \mathrm{R} / \mathrm{NL}$ & $\begin{array}{c}\text { Nonlinear } \\
\text { analysis }\end{array}$ & 149032 & $\begin{array}{c}123 \\
417\end{array}$ & 740286 \\
\hline 3. & $2 \mathrm{P}$ & Linear analysis & 126652 & 147 & 878124 \\
\hline 4. & $2 \mathrm{P} / \mathrm{NL}$ & $\begin{array}{c}\text { Nonlinear } \\
\text { analysis }\end{array}$ & 143084 & 129 & 778482 \\
\hline
\end{tabular}

Numbers of elements in Finite element method for the most effective frame (2R) and shell (2P) structures are provided in table 4. Complexity of building information model is a challenge to designer's PC computer. To define the influence of computational power on calculation time and costs of equipment there were some tests made on two types of PC computer. Calculation times are provided in table 6. At the time of purchase both PC computer prices were the same, while the computing power increased 32-times within 6 years between each being purchased. 
Table 5. PC hardware setups tested with BIM modelling [9].

\begin{tabular}{|c|c|c|}
\hline PC Parts & Setup 1 & Setup 2 \\
\hline Date of Purchase & 2011 & 2017 \\
\hline Processor (Core Speed) & $\begin{array}{c}\text { Intel Core } 2 \text { Quad Q9550 } \\
\text { (4 cores, } 4 \text { threads, 2,86 GHz) }\end{array}$ & $\begin{array}{c}\text { Intel Core i7 7800X } \\
\text { (6 cores, } 12 \text { threads, 5,00 } \\
\text { GHz) }\end{array}$ \\
\hline DRAM & $4.00 \mathrm{~GB}(1066 \mathrm{MHz})$ & $32.00 \mathrm{~GB}(3200 \mathrm{MHz})$ \\
\hline $\begin{array}{l}\text { Nominal Computing } \\
\text { Performance }\end{array}$ & $\begin{array}{c}31 \text { GFLOPS ( } 31 * 109 \text { iterations per } \\
\text { second) }\end{array}$ & $\begin{array}{l}960 \text { GFLOPS }(960 * 109 \\
\text { iterations per second) }\end{array}$ \\
\hline
\end{tabular}

Table 6. Calculation time of selected project stages [9].

\begin{tabular}{|c|c|c|c|}
\hline No. & Stage & Frame structure & Shell structure \\
\hline 1. & $\begin{array}{l}\text { Wind load simulation, } \\
\text { Autodesk Robot }\end{array}$ & \multicolumn{2}{|c|}{$\begin{array}{l}\text { Setup 1: } 3 \mathrm{~h} 47 \mathrm{~min} 17 \mathrm{~s} \\
\text { Setup 2: } 8 \mathrm{~min} 03 \mathrm{~s}\end{array}$} \\
\hline \multirow{2}{*}{2.} & \multirow{2}{*}{$\begin{array}{l}\text { Generating model, } \\
\text { meshing, attribute } \\
\text { assign, model } \\
\text { consolidation }\end{array}$} & Setup 1: $3 \mathrm{~h} 56 \mathrm{~min} 08 \mathrm{~s}$ & Setup 1: $15 \mathrm{~h} 04 \mathrm{~min} 13 \mathrm{~s}$ \\
\hline & & Setup 2: $20 \mathrm{~min} 23 \mathrm{~s}$ & Setup 2: 3h $46 \min 19 \mathrm{~s}$ \\
\hline \multirow{2}{*}{3.} & \multirow{2}{*}{$\begin{array}{l}\text { Calcualtions: } \\
\text { Linear analysis }\end{array}$} & Setup: $1 \mathrm{~h} 25 \mathrm{~min} 13 \mathrm{~s}$ & Setup 1: $6 \mathrm{~h} 13 \mathrm{~min} 00 \mathrm{~s}$ \\
\hline & & Setup 2: $18 \min 32 \mathrm{~s}$ & Setup 2: $42 \min 19 \mathrm{~s}$ \\
\hline \multirow{2}{*}{4.} & \multirow{2}{*}{$\begin{array}{c}\text { Calculations: } \\
\text { Nonlinear analysis }\end{array}$} & Setup 1: $4 \mathrm{~h} 13 \min 18 \mathrm{~s}$ & Setup 1: $21 \mathrm{~h} 57 \mathrm{~min} 31 \mathrm{~s}$ \\
\hline & & Setup 2: $45 \mathrm{~min} 50 \mathrm{~s}$ & Setup 2: $4 \mathrm{~h} 03 \mathrm{~min} 47 \mathrm{~s}$ \\
\hline \multirow{2}{*}{6.} & \multirow{2}{*}{$\begin{array}{l}\text { Glass generation, } \\
2628 \text { elements }\end{array}$} & Setup 1: $7 \min 02 \mathrm{~s}$ & Setup 1: $11 \mathrm{~min} 00 \mathrm{~s}$ \\
\hline & & Setup 2: $1 \mathrm{~min} 08 \mathrm{~s}$ & Setup 2: $1 \mathrm{~min} 51 \mathrm{~s}$ \\
\hline \multirow{2}{*}{7.} & \multirow{2}{*}{ Visualisation } & \multicolumn{2}{|c|}{ Setup 1: $\sim 2$ FPS (frames per second) } \\
\hline & & \multicolumn{2}{|c|}{ Setup 2: 27 FPS (frames per second) } \\
\hline
\end{tabular}

There was noted a 5-times increase in compute and even 28 times increase in wind load simulations. Calculation engines implemented in Autodesk Robot base on CPU computing power, but there is available a new line of linear iterative solvers (Jacobi, Gauss-Seidel, Conjugate, Gradient) used in a rival structural analysis software. They base on graphics cards processing resources, which increase the calculation times up to 20 fold.

\section{Case Study}

The results of the internal forces received for each of the calculation models allow for a broad analysis of the impact of the adopted solutions towards the redistribution and optimization. Model type 1R/ Shell slabs) shall be referred as nominal in a later section. 


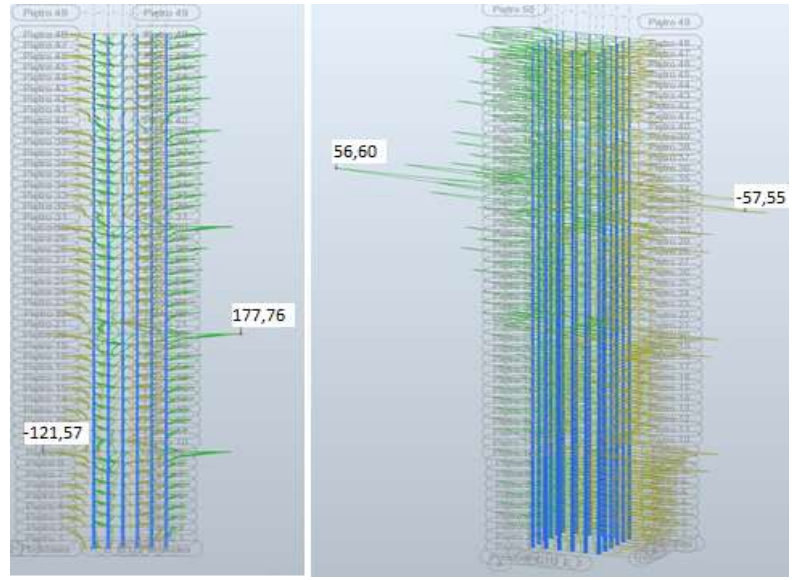

Fig.3. Frame Model 2R: Values of Bending Moments MY [kNm] in the outer pillars: floor slab model type "shell" (left) and "flexible diaphragm" (right).

An important feature of a horizontally concentrated model with floor slabs on each tier fulfilling a stiff slab condition is its influence on the shape of the graph and the values of bending moments in the external pillars (Fig. 4) A noticeable decrease in values of the maximum bending moments MY is related to more effective redistribution of stresses on the poles compared to the solution of the "shell" type. In the case of floors cooperating with the stem, normal forces in steel pillars of the stem are higher by approx. $8 \%$ of the nominal values, there is also a significant increase in the share of bending moments. This means, above all, a reduction of global construction displacements.

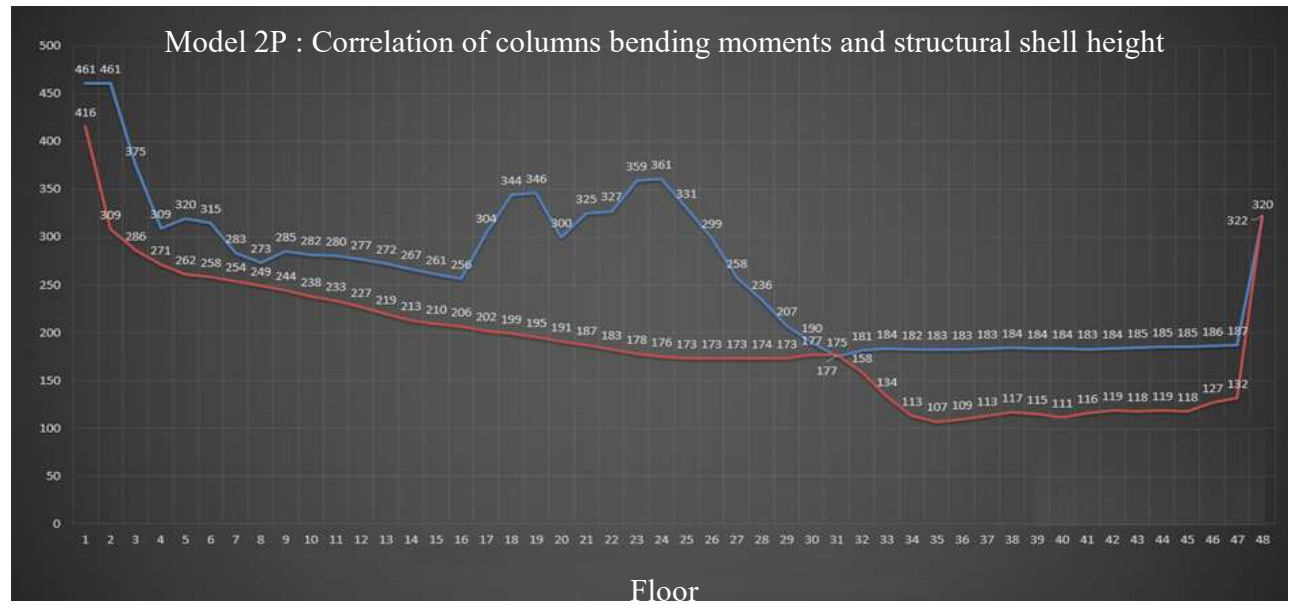

Fig.4. Model 2P Corelation: exterior coating columns bending moments MY [kNm] and overall height; blue line - flexible diaphragm slab model, red line - shell slab model.

The stiffening of "flexible diaphragm" had also influenced the reduction of values of bending moments in the beams of the transverse frames and had a significant influence on the selection of the profiles of these beams. The impact of the solution of the floor slab model was also noticed in shell models. According to the assumption of the shell structure, its outer casing takes over part of the horizontal loads from the core. The graph of the dependance of bending moments in the case of the pillar concentration with rigid plates indicates their significant stiffening and a more compensated response to the impact. Substrings rigidly fixed with the outer pillars also take over the forces directly from the ceilings and carry them 
onto the stem. Additional concentration of the construction by the rigid plate design causes an increase of redistribution of normal forces and bending moments from the pillars. There has been an increase in the values of internal forces in beams of the outer casing and in the stem pillars, due to the way of stiffening, this leads to greater use of the bearing capacity of these components at the place of the skyscraper's outer casing.

The information obtained from calculation models indicate a significant contribution of horizontal forces. It's reflected by the chart of global pillars effort (Fig. 5): for tiers 1 to 38, state of boundary use was reached as the first condition, leaving a considerable supply of safety for the limit state of boundary load.

The computational models prepared in BIM class systems enable accurate cost estimation of the project based on the entered data. For example, Structure Weight Information was obtained. Working with models in this standard allows for a quick verification of vast amount of information about the building or creation of data sets for further analysis. The software is adapted to the applicable building and legal standards (including foreign) on building documentation in digital form.

The results analysis shows that the share participation of the pillars in transferring the horizontal load acting on the structure varies according to the method of modeling the concentrations. The displacement received for the design version equals $\mathrm{H} / 2909$ for the shell structure and $\mathrm{H} / 1600$ for the framework structure in view of the used normalization of limitation for the building inclination $\mathrm{H} / 500$ (Table 1).

Model 2P : Level of load capacity (ULS) and level of limit states (SLS)

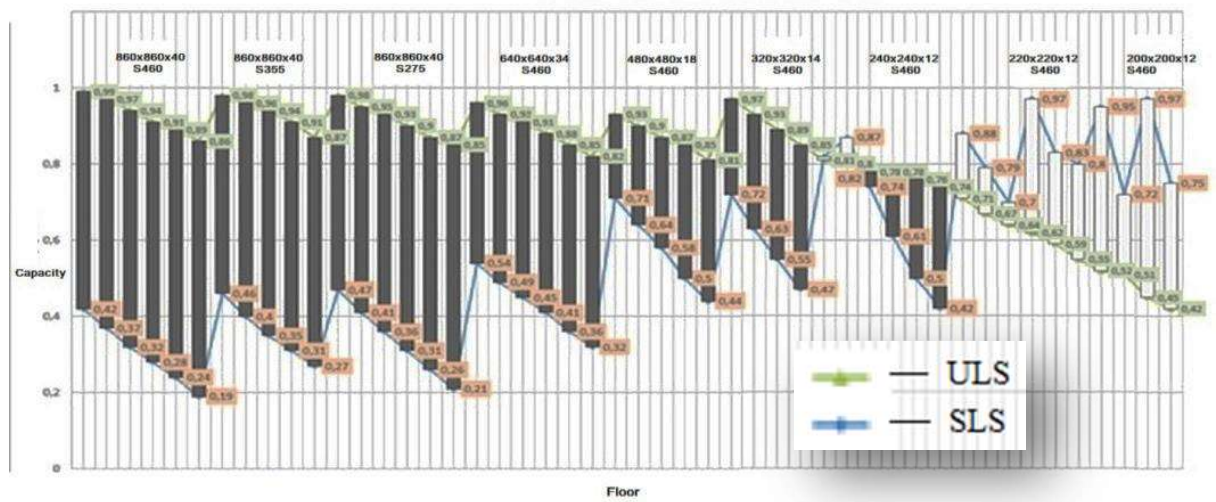

Fig. 5. Model 2P / Shell slab model: Level of load capacity (ULS) and level of limit states (SLS) in columns.

\section{Model of construction as the element of designing in BIM system}

The basic tool of structural designer's work in BIM environment is the programme for calculations and analysis of building structure with ability to exchange of bidirectional data with other programmes. In this case study Autodesk Software was used. This work environment includes a few programmes work with different files extensions, allowing to exchange of data both inside the system and outside. Among the standards the data structure model with Industry Foundation Class (IFC) file extension is distributed. It should be pointed out that according to BIM's philosophy, specialist software of different producers will be developed in order to interoperability. Complex structure of high-rise building and also probable amount of architectural details or installation systems indicate BIM software as 
finished and at the same time as opened system of solutions for design offices. Programme alerts participants of project process about identified collisions, showing practically infallibility. BIM software allows also to create an intelligent planning model of construction projects - as 4D BIM (Fig. 6).

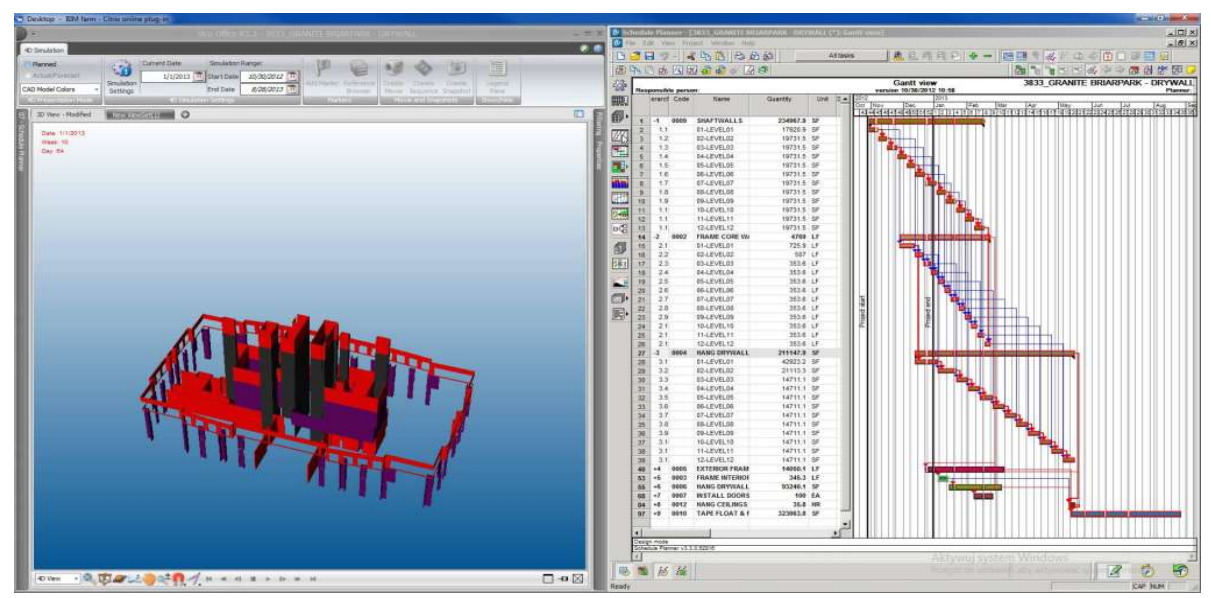

Fig. 6. Prototype scheduling of works in BIM community [9]: a) visualisation; b) achedule of works.

Calculation models prepared in BIM systems enable accurate design costs analysis (5D) on the basis of entered data. By way of example, information about weight of construction was obtained. Working with models in this standard allow for fast verification of huge amounts of information about building or production of sets of data for further analysis. The software is adapted to existing (also foreign) codes and standards relating to construction documentation in digital form.

Table 7. Weights of steel construction in analysed calculation models [9].

\begin{tabular}{|c|c|c|}
\hline Name of model & Weight of steel construction [kg] & Relative reference \\
\hline 1R / Shell & 6049832 & $\mathbf{1 0 0 . 0 \%}$ \\
\hline 1R / Diaphragm & 6080081 & $100.5 \%$ \\
\hline 2R / Shell & 6244618 & $103.2 \%$ \\
\hline 2R / Diaphragm & 6275841 & $103.7 \%$ \\
\hline Name of model & Weight of steel construction [kg] & Relative reference \\
\hline 1P / Shell & 6341317 & $\mathbf{1 0 0 . 0 \%}$ \\
\hline 1P / Diaphragm & 6371566 & $100.5 \%$ \\
\hline 2P / Shell & 6698233 & $105.6 \%$ \\
\hline 2P / Diaphragm & 6728482 & $106.1 \%$ \\
\hline
\end{tabular}

Designer has got a tool to fully submission of all of information about his product in the form of one file. The model seems to understand changes, adapts important layers of project, geometric elements, quantity statements or time schedule of construction works in dynamic way. Revit programme indicated significant difference of glazing area in developed models of steel structure of high-rise building (Table 8), which may decide about the choice of particular solution because of the possible costs. 
Table 8. Estimated cost of material of glazing determined in Revit programme [9].

\begin{tabular}{|c|c|c|c|}
\hline Name of model & Glazing area $\left[\mathrm{m}^{2}\right]$ & Unit price [PLN] & Overall cost [PLN] \\
\hline Frame structure model $2 \mathrm{R}$ & 15683.2 & \multirow{2}{*}{137} & 2148598.40 \\
\hline Shell structure model 2P & 8933.7 & & 1223914.16 \\
\hline
\end{tabular}

The possibility of visualisation of product is crucial for many people. BIM software enables to create intelligent digital elevation models in 3D from laser scans as well as photorealistic and interaction visualisation. For this purpose, models were designed in Robot+Revit+3dsMax framework with Nvidia IRAY plugin and graphics engine. Such elaborate system allows, for example, to ,walk" through further spaces or amend parameters of numerical model. What is more, these changes are noticed by any of BIM software in real-time. The system makes it possible to update calculations constantly, directly from 3D and VR (Virtual Reality) vision.
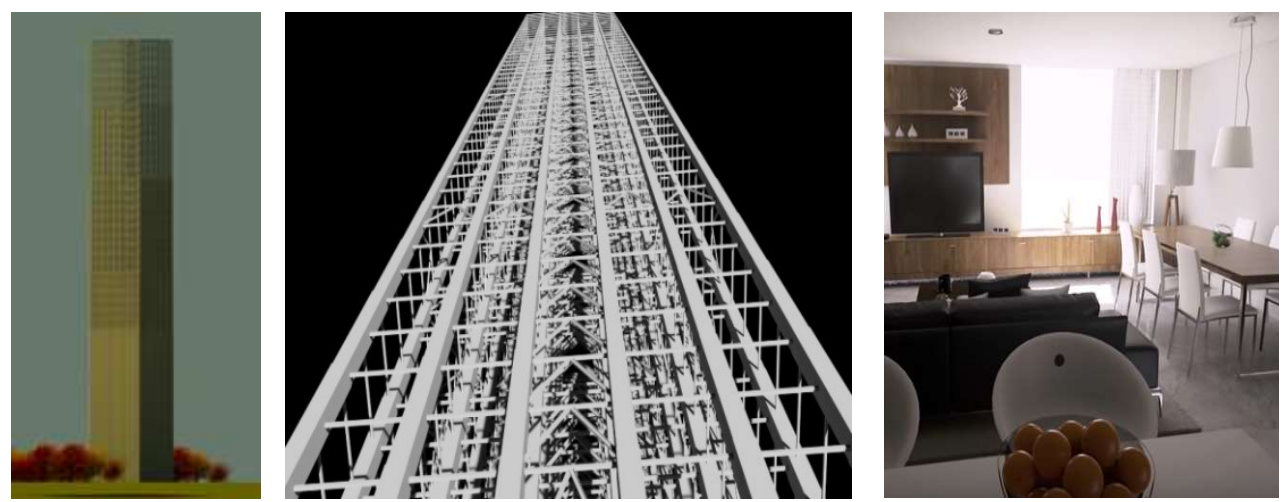

Fig.7. The parts of visualisation in programmes: from the left: Revit, 3dsMax, Nvidia IRAY Virtual Reality (VR) [9].

\section{Conclusion}

In mechanics, where CAD systems had been developed, the system of fast prototyping has functioned for so long. Nowadays, this working scheme comes in wider civil engineering, allowing more accurate way of analysis of solutions and presentation of model than it has ever been.

Analyzed case study of steel structure of the high rise building shown that using slabs meeting the conditions of a rigid plate cause better interaction of structural elements (Fig. 3, 4). Spatial stiffness of the structure is ensured and internal forces are better distributed, overall weight of the steel constructions is comparable (Table 7). Consequently, the parameter of global deflection of the structure vary significantly. To high rise buildings critical requirement is SLS. Furthermore, high rise buildings using shell structure, diaphragm slabs and core (type 2P Flexible diaphragm) characterises them as the most rigid. Complex calculation models providing multi-attribute building information need a very fine PC configurations (Table 5), which has a great impact on calculation times.

It seems that the possibility of showing model of construction and structure in virtual way (virtual reality headsets for example), will redefine the way of cooperation between sides of investment project, understanding changes in model as changes tens of parameters of structures which are in correlation with the change in dimension of time, costs and other required in facility lifecycle. In the authors' opinion the rapidly advancing digital revolution of CAD-BIM systems, will result in increase in productivity of designers, create new working 
positions, where constructor's knowledge from the scope of structural mechanics, designing of constructions, programming and computer graphics, will help him to take over the role of the leader of design process, which was reserved for architects until now. The perspective on the structure from the aspect of its lifecycle will serve as the key to cooperation with future environmental challenges in civil engineering .

\section{References}

1. D. Migilinskas, V. Popov, V. Juocevicius, L. Ustinovichius, The Benefits, Obstacles and Problems of Practical Bim Implementation, Procedia Engineering Volume 57, p.767774 (2013)

2. A. Deshpande, S. Azhar, S. Amireddy, A Framework for a BIM-based Knowledge Management System, Procedia Engineering Volume 85, p.113-122 (2014)

3. I. Sutherland, A head-mounted three dimensional display, In: Proceedings of FJCC, Thompson Books, Washington DC, p.757-764 (1968)

4. C. A. Hunt, The Benefits of Using Building Information Modeling in Structural Engineering, All Graduate Plan B and other Reports 319 (2013)

5. W. Natephra, A. Motamedi, T. Fukuda, N. Yabuki, Integrating building information modelling and virtual reality development engines for building indoor lighting desigh, Visualization in Engineering (2017)

6. A. A. Bhusar, A. R. Akhare, Application of BIM in Structural Engineering, SSRG International Journal of Civil Engineering (SSGR-IJCE) - volume 1 Issue 5 October (2014).

7. L. Maia, P. Meda, J. G. Freitas, BIM methodology, a new approach - case study of structural elements creation, Procedia Engineering, p.816-823 (2015)

8. Rowan de Graaf Producing Virtual Walkthroughs from Architectural Models: a case study of the New University Building, Universiteit Van Amsterdam (2015)

9. B. Żymańczyk, Master's Dissertation: Study design with the BIM elements of the steel construction multi-storey building with the different bracing systems, Opole University of Technology (2017)

10. A. Z. Pawłowski, I. Cała, High rise buildings, Warsaw University of Technology Publishing House, Warsaw (2013)

11. A. Tomana, BIM, Innovative technology in Civil Engineering, PWB Media Builder, Warsaw (2016)

12. J. Żmuda, Steel structure design (part 2), PWN, Warsaw (2016)

13. Eurocode PN-EN 1990:2004, Basic of structural design

14. Eurocode PN-EN 1991-1-1:2004, Densities, self-weight, imposed loads for buildings

15. Eurocode PN-EN 1991-1-3:2005, General actions - Snow loads

16. Eurocode PN-EN-1991-1-4:2005, General actions - Wind actions

17. Eurocode PN-EN-1993-1-1:2006, Design of steel structures, General rules and rules for buildings

18. ASCE/SEI 7, Minimum Design Loads For Buildings and Other Structures 